\section{Physics in the Greenhouse}

\author{
Balances in the Atmosphere and the Energy Problem \\ Bad Honnef, 4-7 February 1990
}

It is difficult when Europe is enjoying exceptionally high temperatures not to believe that we are witnessing the effects of modifications to the atmosphere. However, we should beware of drawing too hasty a conclusion, even though the evidence is mounting that a continuing rise in world temperature has to be expected.

In Bad Honnef at the Physikzentrum of the Deutsche Physikalische Gesellschaft from 4-7 February 1990, experts from a number of European countries came together to exchange their views in a Seminar organised by the W-E Heraeus Stiftung in cooperation with the (former) Advisory Committee on Physics and Society. Entitled "Balances in the Atmosphere and the Energy Problem" it followed on from the Europhysics Study Conference "Induced Critical Conditions in the Atmosphere and the Energy Problem" held in Torino last September (see Europhysics News 21 35). The meeting was designed to update our knowledge of the greenhouse effect, examine current models and consider how emissions of $\mathrm{CO}_{2}$ and other greenhouse gases could be contained.

\section{The Evidence}

Historical data on the Earth's temperature and atmospheric $\mathrm{CO}_{2}$ content now seems well established from isotopic measurements of ice cores. Curves from Leningrad matched those from Hamburg and the general correlation was indisputable. However, there is no way of distinguishing cause from effect in the distant past and the drive may well have been the temperature resulting from astronomical changes. Nevertheless, it is tempting to blame the temperature rise since the beginning of the industrial revolution on the $\mathrm{CO}_{2}$ build up although there are some disturbing anomalies, for example the decrease observed in the northern hemisphere between 1940-1970.

Not that $\mathrm{CO}_{2}$ is the only greenhouse gas. Had it not been for the efforts made to limit the release of CFC's, they would probably by now be more important than $\mathrm{CO}_{2}$. As it is they contribute up to $25 \% . \mathrm{NO}_{\mathrm{x}}, \mathrm{CH}_{4}$ and other gases must also be considered and not least water vapour. In the continuum band, water vapour is the main IR absorber and the atmosphere in the tropics has an optical depth of unity.

General circulation models which ignore clouds agree with each other reasonably well, but the moment one tries to incorporate cloud effects then the divergences become marked. Current wisdom indicates an increase in temperature of $3.0 \pm 1.5^{\circ} \mathrm{C}$ for a doubling of the $\mathrm{CO}_{2}$ equivalent content implying a rise in the sea level from thermal expansion alone of about $50 \mathrm{~cm}$. This is enough in a country like The Netherlands to require huge investments to stem the tide. Unfortunately, none of the models can be relied on to give any information on regional variations, and precipitation fore-

Mean atmospheric $\mathrm{CO}_{2}$ concentration versus time, based upon Antarctic ice core data from Siple Station ( $\triangle$ and $O)$, Station D57 (घ), and Law Dome (4), modern air concentration measurements at Mauna Loa, Hawaii (-), and some nineteenth century air concentration measurements at a number of sites around the world.

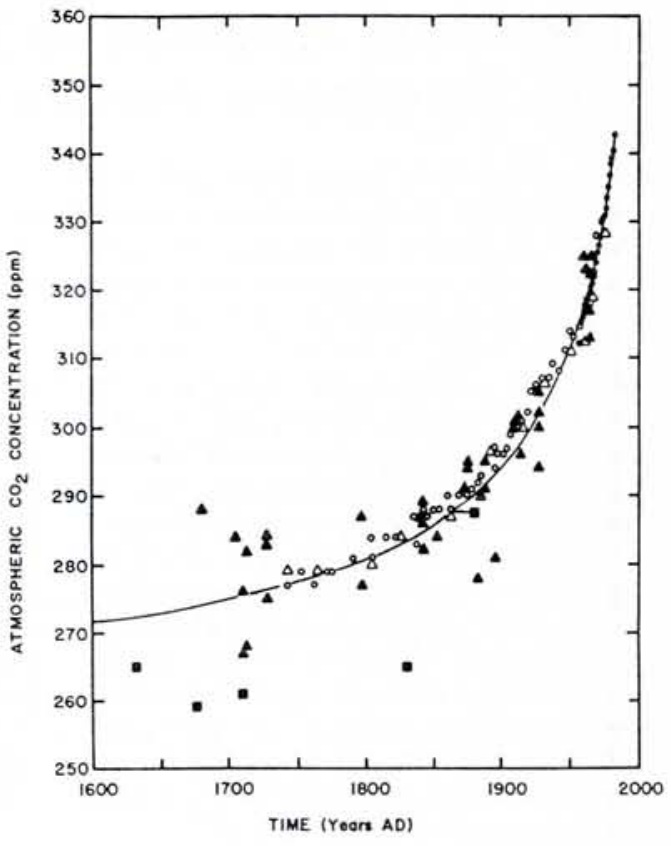

casts must be regarded with great scepticism. As reported in Torino, there is strong evidence that over the past 150 years there has been a shift in precipitation to higher latitudes, yet historically N. Africa became wetter in the hotter periods. The difference could be ascribed to the speed of build-up of $\mathrm{CO}_{2}$ if the models could be trusted.

Still more serious was the charge made at the Seminar that the impact of the biomass was being totally neglected and yet it could be the dominant item. $\mathrm{CO}_{2}$ stimulates growth, not just of trees, and this could mean there was a big negative feed-back out there in the countryside. All in all, it is clear that much more research is needed to evaluate all the elements contributing to this hugely complex problem - and to attach numbers to them.

\section{What to Do}

In the mean time it would be fool hardy not to assume that a more than desirable rise in temperature could materialize as the world's population grows - if only because the time constants are such that any action will take years to bite. So what can be done - technically? It will be for the public at large to decide what balances to make of different risks and what priorities to attach to different scenario.

Extraction of $\mathrm{CO}_{2}$ from power station emissions is one approach, and then to dispose of the $\mathrm{CO}_{2}$ by, say pumping it into exhausted gas fields, dumping it as solid into the deep oceans or recycling it through conversion by microalgae. The ideas are sound, but are the economics?

Some enthusiasts would have us believe that solar cells can provide the answer - at a cost that depends heavily on the assumptions you make about future efficiencies and production costs. Others would have us go back to a wood economy, although stacking cut trees in some distant desert defies the imagination.
Fission and, in the very long term, fusion offer a way out, but only if we can be convinced that the risks are reduced to an acceptable level, and we can solve the problem of public understanding. Regrettably in the fission field, short-term economics and emotional opposition have now seriously limited the contribution nuclear energy could make in the near-term. All the more reason for reevaluating our reactor designs and looking at systems and fuel cycles that have been left on the shelf. It was interesting that in Bad Honnef the $\mathrm{Th}_{223} \mathrm{U}$ cycle was not even mentioned.

Biomass farming is another area worthy of serious attention. Reference was made to the Brazilian experiment on the production of alcohol as liquid fuel which has been rather more successful than some reports have suggested. New strains of sugar cane, better adapted to machine cutting, are providing fodder, fuel and fertiliser from the same plant. Wind and waves too can contribute in small measure in certain regions, but as with the renewables (hydro apart), one comes up against the fundamental problem of energy storage. It seems that we are not so far from the limit of what is possible in storage batteries. The general conclusion is that none of the alleviating measures should be neglected, at least until its unpracticality has been demonstrated. The inherent inertia in our ways of life and the limit to investment both exclude slick solutions.

So what is the message? Essentially it is more research, more experiment and especially further prototype plants. In the early days of nuclear fission, it was said that all the best reactors were paper moderated and ink cooled. We need better data all along the line: substantial investment in studies and building a scientific attitude to problems. It will be the numbers that count in the end, not the hand waving.

E.N. Shaw, Geneva 